SPECIAL ISSUE

\title{
THE STATE OF THE ART OF PHYSICAL MEDICINE AND REHABILITATION IN NEW ZEALAND
}

\author{
Guest Editors \\ Richard Seemann \& Michael S. Kaplan
}

\section{PREFACE}

We as guest editors are pleased to showcase research and reviews of the state of the art of Physical Medicine and Rehabilitation (PMR) in New Zealand. Although we are a relatively small country of only 4.5 million inhabitants, research and expertise in areas of rehabilitation and physical medicine has been increasing in prominence for several decades. Our clinicians and researchers are gradually expanding a multidisciplinary PMR model within our health care system. As a publicly funded system, we are able to embrace health care throughout the continuum of life. Promotion of health and prevention of disease are the cornerstone of multidisciplinary care regardless of age.

Unlike many larger countries we have embraced a complementary model of treatment of accidental injury (through universal no-fault insurance under the Accident Compensation Corporation) and dysfunction caused by disease (through governmentfunded rehabilitation services associated with public hospitals). Regardless of the cause of a person's dysfunction, we feel fortunate that health care is provided for all illness and disability. Payment is not the prominent concern of our health care system; instead, quality treatment in a nonthreatening environment is critical to our society.

Rehabilitation conferences are typically attended in accordance with the PMR multidisciplinary model. As a small country we generally do not have PMR conferences for only a single discipline because they would not be affordable to the few attendees. We feel our open-access system and easy accessibility have become our strengths and that they enhance a more unified approach to health care.

Members of the 2 main nongovernmental organizations involved in PMR in New Zealand, the New Zealand Rehabilitation Association and the Australasian Faculty of Rehabilitation Medicine, have contributed to this special edition, together with a number of university academics. We have 3 rehabilitation studies departments in our university system (at the University of Otago, Massey University, and the Auckland University of Technology [AUT]), and these offer graduate and postgraduate programs in this field.

As Guest Editors of this special edition, we have selected local clinicians and researchers who make regular contributions in their respective fields. Our selected emphasis for this journal has been neurorehabilitation, but readers should not be left with the impression 
that this is the primary focus in New Zealand. For example, rehabilitation of the older adult is also important. We have integrated prevention programs and falls reduction programs for seniors throughout the country, with centers of excellence for "Older Persons and Rehabilitation" at many hospitals. Michael Kaplan, $\mathrm{MD}, \mathrm{PhD}$, has recently been appointed as the Senior Medical Officer at Waikato Hospital's Older Persons and Rehabilitation Service, which opened The Institute of Healthy Aging in 2013. Both nursing and physiotherapy graduate students are now enrolled there under the supervision of Dr. Kaplan, together with Matthew Parsons, $\mathrm{PhD}$, and John Parsons, $\mathrm{PhD}$. We are confident that the younger group of students and researchers will further the therapeutic aspects of PMR.

In this issue, Dr. Kaplan has coauthored an article on neurogenesis together with Drs. Prasadarao, Parsons, Parsons. This expands his pioneering work, which has now blossomed into a realistic clinical goal for many clinical conditions. Their article reviews the clinical implications that may affect our views toward rehabilitation practices and recovery.

Dr. Richard Seemann, MD, has written about prognostication in traumatic brain injury from the perspective of the country's largest brain injury program at ABI Rehabilitation New Zealand Ltd.

Harry McNaughton, MD, Kathryn McPherson, $\mathrm{PhD}$, and their colleagues from AUT and the University of Auckland have combined to produce a thoughtful article on the content of stroke rehabilitation and dosing that may serve to alter the design of stroke services in New Zealand and, we hope, in other countries as well. The special context of Maori (the indigenous people of New Zealand) and their engagement in rehabilitation is also explored in this article.

We also are pleased to have a review article by Gwyn Lewis, $\mathrm{PhD}$, and David Rice, $\mathrm{PhD}$, from AUT, on the major role of neuroplasticity in chronic pain, an important topic in the context of long-term disability.

Duncan Babbage, $\mathrm{PhD}$, a neuropsychologist, has written about his personal research into difficulties with recognizing emotions after brain injury. He has recently been appointed to a senior position in the Health and Rehabilitation Research Institute at AUT under the auspices of Kathryn McPherson.

We should make special mention of Shaun Xiong, MD, and his colleagues at the Burwood Spinal Unit, New Zealand's major spinal injury unit, which was damaged in the Christchurch earthquake of 2011. Despite having to endure repeated earthquakes and disruption to their unit, they have written an excellent review of their approach to the patients with spinal cord injury and the current fields of research in which they are involved.

Sean Mathieson, PT, has partnered with John Parsons and Michael Kaplan to write 2 articles. The first is on the current evidence for combination therapy with functional electrical stimulation and mirror therapy for the hemiplegic upper limb. The second is a case study highlighting therapies for fine motor control of hand affected by stroke.

Overall we are heartened by the many offers of articles and the level of commitment to PMR within this small country. We are confident that these areas of research will lead to improved clinical practice throughout New Zealand and, we hope, stimulate others to 
work on improving our knowledge base in PMR. We hope you enjoy the articles presented in this special edition.

Dr. Richard Seemann ABI Rehabilitation New Zealand Ltd Auckland, New Zealand

Michael S. Kaplan Older Persons and REhabilitation Service Waikato District Health Board Hamilton, New Zealand 
